\title{
Shear Stress Attenuates Inward Remodeling in Cultured Mouse Thoracodorsal Arteries in an eNOS-Dependent, but Not Hemodynamic Manner, and Increases Cx37 Expression
}

\author{
Robin C. Looft-Wilson ${ }^{a-d}$ Janelle E. Billig ${ }^{d}$ William C. Sessa ${ }^{a-c}$ \\ a Department of Pharmacology, Yale University School of Medicine, New Haven, CT, USA; \\ ${ }^{b}$ Department of Cardiology, Yale University School of Medicine, New Haven, CT, USA; \\ 'Vascular Biology and Therapeutics Program, Yale University School of Medicine, New Haven, CT, USA; \\ ${ }^{\mathrm{d}}$ Department of Kinesiology and Health Sciences, College of William and Mary, Williamsburg, VA, USA
}

\section{Keywords}

Flow · Remodeling · eNOS · Connexins · Gap junctions

\begin{abstract}
Background: Arteries chronically constricted in culture remodel to smaller diameters. Conversely, elevated luminal shear stress (SS) promotes outward remodeling of arteries in vivo and prevents inward remodeling in culture in a nitric oxide synthase (NOS)-dependent manner. Objectives: To determine whether SS-induced prevention of inward remodeling in cultured arteries is specifically eNOS-dependent and requires dilation, and whether SS alters the expression of eNOS and other genes potentially involved in remodeling. Methods: Female mouse thoracodorsal arteries were cannulated, pressurized to $80 \mathrm{~mm} \mathrm{Hg}$, and cultured for 2 days with low SS $\left(<7 \mathrm{dyn} / \mathrm{cm}^{2}\right)$, high SS $\left(\geq 15 \mathrm{dyn} / \mathrm{cm}^{2}\right)$, high SS + L-NAME (NOS inhibitor, $10^{-4} \mathrm{M}$ ), or high SS in arteries from eNOS-/- mice. In separate arteries cultured 1 day with low or high SS, eNOS and connexin (Cx) 37, Cx40, and Cx43 mRNA were assessed with real-time PCR. Results: High SS caused little change in passive diameters after culture $(-4.7 \pm 2.0 \%)$, which was less than low SS $(-18.9 \pm 1.4 \%$; $p<$ $0.0001)$, high SS eNOS-/- $(-18.0 \pm 1.5 ; p<0.001)$, or high
\end{abstract}

\section{KARGER}

(c) 2019 S. Karger AG, Basel

E-Mail karger@karger.com

www.karger.com/jvr
SS + L-NAME $(-12.0 \pm 0.6 \%$; nonsignificant $)$ despite similar constriction during culture. Cx37 mRNA expression was increased $(p<0.05)$ with high SS, but other gene levels were not different. Conclusions: eNOS is involved in SS-induced prevention of inward remodeling in cultured small arteries. This effect does not require NO-mediated dilation. SS increased Cx37.

C) 2019 S. Karger AG, Basel

\section{Introduction}

Arteries remodel in response to chronic hemodynamic or vasomotor changes. For example, chronic increases in flow in vivo promote reorganization of cellular constituents to form a larger luminal diameter, called outward remodeling, and chronic decreases in flow promote a smaller luminal diameter, called inward remodeling [1-7]. Additionally, chronic vasoconstriction, as typically occurs with essential hypertension, leads to inward remodeling [8-11], and sustained vasodilation leads to outward remodeling [11]. Increased flow, and the resulting increased shear stress (SS), is well known to stimulate the production of nitric oxide (NO) [12], but the role of $\mathrm{NO}$ 
in remodeling is less clear. In vivo inhibition of NO synthase (NOS) has been reported to prevent flow-induced remodeling in many [13-15] but not all cases [16, 17]. Moreover, NO is known to have antiproliferative effects that could potentially counter the remodeling process [18-21]. It is also unclear from in vivo studies whether the role of NO in shear-induced remodeling is based on its effect on vasomotor tone and diameter, or its effect on growth processes.

Isolated arteries maintained in organ culture have been useful in helping to dissect the stimuli that can produce remodeling, because this method allows precise control of hemodynamic parameters such as pressure and flow, and eliminates neurohumoral influences and remote factors such as tissue ischemia. This approach has been most useful for studying inward remodeling. For example, chronic exposure to a variety of vasoconstrictors under constant luminal pressure has been shown to induce inward remodeling of cultured arterioles over a time course of $4 \mathrm{~h}$ to 3 days [22-25]. Adding luminal flow in the physiological range was shown in a study by Pistea et al. [26] to prevent this inward remodeling in porcine coronary arteries. This effect was eliminated by NOS inhibition (using L-NNA), indicating that flow-induced prevention of inward remodeling is NOS dependent.

The purpose of this study is to extend the findings of Pistea et al. [26] to the mouse, which allows use of a genetically deficient model. The objective was to examine whether elevated luminal SS would prevent inward remodeling in cultured thoracodorsal arteries (a small artery) [27] and whether NOS and specifically endothelial NOS (eNOS) is involved by using arteries from eNOS-/mice. The second objective was to examine expression of select genes during acutely increased SS ( $20 \mathrm{~h}$ in culture). We measured eNOS mRNA expression to determine whether SS alters this gene in cultured arteries as it does in cultured endothelial cells [28-33]. We also measured the vascular gap junction genes connexin $(\mathrm{Cx}) 37, \mathrm{Cx} 40$, and $\mathrm{Cx} 43$, as these are involved in vasomotor control through mediation of endothelial-dependent hyperpolarization [34] and arterial response to SS, and implicated in remodeling [35-40]. In addition, comparing the expression of these genes between high and low SS conditions provided a way to determine whether low SS conditions lead to deterioration of vasomotor control pathways in culture. This study revealed that SS-induced prevention of inward remodeling is eNOS dependent but does not require chronic dilation. In addition, $\mathrm{Cx} 37 \mathrm{mRNA}$ was increased, while the other genes selected are not altered.

eNOS-Dependent SS Remodeling and Increased Cx37 Expression

\section{Methods}

This study had 2 parts. The objective of part 1 was to test the effect of luminal flow, and the calculated SS, on inward remodeling in mouse thoracodorsal arteries after 2 days of culture and the contribution of eNOS to this process. The objective of part 2 was to measure the effect of flow on the expression of genes responsive to SS after 1 day of culture.

Part 1: Remodeling Response to SS and Contribution of eNOS

Female mice (14.8 \pm 0.5 weeks old; range 7-26 weeks) of wildtype (chimeric C57BL6/129 or C57BL6) and eNOS-/- mouse (Jackson Labs) genotypes were used in this study. Most of the wildtype mice were chimeric C57BL6/129, the same background as the eNOS-/- mice, but due to limited populations, these were supplemented with C57BL6. Four different treatments were designed to test the effects of high and low SS on inward remodeling and the contributions of NOS and eNOS on the effects of high SS. The treatment groups were (1) arteries from wild-type mice with low flow and SS $<7 \mathrm{dyn} / \mathrm{cm}^{2}$ (low SS), (2) arteries from wild-type mice with high flow and $S S \geq 15 \mathrm{dyn} / \mathrm{cm}^{2}$ (high SS), (3) arteries from wild-type mice with high SS and L-NAME $\left(10^{-4} \mathrm{M}\right)$, a general NOS inhibitor, in the superfused culture medium (high SS + L-NAME), and (4) arteries from eNOS-/- mice with high SS (high SS eNOS-/-).

Mice were anesthetized with xylazine/ketamine (3.2 and 34 $\mathrm{mg} / \mathrm{kg}$, respectively, i.p. or i.m.), and thoracodorsal arteries were isolated and placed in an organ chamber (Culture Myograph, 202 EvB; Danish Myo Technology, Aarhus, Denmark) containing fresh, chilled MOPS-buffered physiological salt solution (PSS; in mM: $145 \mathrm{NaCl}, 4.7 \mathrm{KCl}, 2.0 \mathrm{CaCl}_{2}, 1.17 \mathrm{MgSO}_{4}, 1.2 \mathrm{NaH}_{2} \mathrm{PO}_{4}, 2.0$ MOPS, 0.02 EDTA, 5.0 glucose, 2.0 pyruvate, $\mathrm{pH}$ 7.4, sterile filtered). Mice were euthanized by an overdose of xylazine/ketamine (i.p.). A total of 84 mice were used, with 1 thoracodorsal artery isolated from each mouse, except for 5 mice in which 2 arteries were isolated, for a total of 89 arteries.

Arteries were cannulated and secured with 8-0 nylon suture on one end, blood was gently cleared from the lumen, and the other end was cannulated and secured. Arteries were pressurized to 80 $\mathrm{mm} \mathrm{Hg}$ using a pressure manometer and equilibrated for approximately $30 \mathrm{~min}$ at $37^{\circ} \mathrm{C}$ in MOPS-buffered PSS. Preculture artery integrity was tested by vasoconstriction to phenylephrine (PE; $10^{-5}$ M) to approximately $50 \%$ baseline diameter, followed by $\geq 80 \%$ vasodilation to acetylcholine (ACh; $10^{-5} \mathrm{M}$ generally, with $10^{-6}$ or $10^{-4} \mathrm{M}$ used in a few arteries): dilation $(\%)=$ (diameter with ACh - preconstricted diameter)/(maximal diameter - preconstricted diameter $\times 100$. Diameters were measured using a $10 \times$ objective, CCD camera, and Vediview software (DMT-USA, Inc., Atlanta, GA, USA). The artery was fully dilated with $10^{-4} \mathrm{M}$ papaverine (passive diameter). In some arteries, passive diameters were determined from the dilation to ACh, which resulted in full dilation to baseline diameter and was found to be nearly identical to diameters with papaverine. Passive diameters were also measured at $20,40,60,80,100$, and $120 \mathrm{~mm} \mathrm{Hg}$ in the presence of papaverine $\left(10^{-4} \mathrm{M}\right)$ in most arteries before and after culture. The chamber was then flushed for at least $10 \mathrm{~min}$. In general, only single dose-responses to drugs were performed in order to minimize the exposure of arteries to vasoactive substances before culturing [41].

Arteries were then cultured for 2 days in Lebovitz medium (L15; JRH Biosciences, Lenexa, KS, USA) supplemented with L-glutamine (2.8 mM; Mediatech, Inc., Herndon, VA, USA), penicillin/ 
Table 1. Artery luminal flow, diameter, and luminal shear stress (SS; mean \pm SEM) during 2-day culture

\begin{tabular}{|c|c|c|c|c|}
\hline & $\begin{array}{l}\text { Low SS } \\
(n=7)\end{array}$ & $\begin{array}{l}\text { High SS } \\
(n=12)\end{array}$ & $\begin{array}{l}\text { High SS } \\
+ \text { L-NAME } \\
(n=5)\end{array}$ & $\begin{array}{l}\text { High SS } \\
\text { eNOS-I- } \\
(n=8)\end{array}$ \\
\hline Average culture diameter, $\mu \mathrm{m}$ & $101 \pm 6$ & $109 \pm 4$ & $91 \pm 5$ & $76 \pm 7^{* * \dagger}$ \\
\hline $\begin{array}{l}\text { Average culture diameter relative to passive diameter } \\
\text { before culture, } \%\end{array}$ & $42.0 \pm 2.8$ & $48.2 \pm 2.1$ & $39.4 \pm 2.2$ & $41.3 \pm 4.1$ \\
\hline \multicolumn{5}{|c|}{ Average flow rate, $\mu \mathrm{L} / \mathrm{min}$} \\
\hline Day 1 & $4 \pm 1$ & $35 \pm 6$ & $23 \pm 3$ & $25 \pm 3$ \\
\hline Day 2 & $3 \pm 1$ & $37 \pm 8$ & $23 \pm 6$ & $18 \pm 3$ \\
\hline Overall & $3 \pm 1$ & $36 \pm 7^{\dagger \dagger \dagger}$ & $23 \pm 4$ & $21 \pm 3$ \\
\hline Average luminal SS, dyn $/ \mathrm{cm}^{2}$ & $3.4 \pm 0.6$ & $36.3 \pm 8.5^{++}$ & $37.5 \pm 5.9^{+++}$ & $76.8 \pm 27.2^{\dagger+}$ \\
\hline Range & $1.7-6.6$ & $14.7-121.2$ & $15.2-47.3$ & $15.0-256.8$ \\
\hline Culture time, $\mathrm{h}$ & $44.5 \pm 0.7$ & $44.2 \pm 0.5$ & $45.1 \pm 0.6$ & $44.1 \pm 0.5$ \\
\hline
\end{tabular}

Table 2. Artery diameters and pharmacological responses (mean \pm SEM) before (pre) and after (post) 2-day culture

\begin{tabular}{|c|c|c|c|c|}
\hline & $\begin{array}{l}\text { Low SS } \\
(n=7)\end{array}$ & $\begin{array}{l}\text { High SS } \\
(n=12)\end{array}$ & $\begin{array}{l}\text { High SS } \\
+ \text { L-NAME } \\
(n=5)\end{array}$ & $\begin{array}{l}\text { High SS } \\
\text { eNOS-/- } \\
(n=8)\end{array}$ \\
\hline \multicolumn{5}{|c|}{ Baseline diameter, $\mu \mathrm{m}$} \\
\hline Pre & $232 \pm 7$ & $222 \pm 4$ & $220 \pm 8$ & $178 \pm 8^{* *}$ \\
\hline Post & $158 \pm 7^{\dagger \dagger \dagger}$ & $130 \pm 9^{\dagger \dagger \dagger}$ & $154 \pm 13^{\dagger \dagger}$ & $118 \pm 7^{\S \dagger \dagger}$ \\
\hline \multicolumn{5}{|c|}{$\mathrm{PE}, \%$ of passive diameter } \\
\hline Pre & $39.0 \pm 2.8$ & $43.2 \pm 3.5$ & $45.0 \pm 6.6$ & $38.9 \pm 5.2$ \\
\hline Post & $38.8 \pm 5.2$ & $29.9 \pm 5.1$ & $30.0 \pm 3.4$ & $31.4 \pm 5.3$ \\
\hline \multicolumn{5}{|c|}{ ACh, $\%$ dilation } \\
\hline Pre & $90.0 \pm 8.1$ & $98.5 \pm 0.9$ & $96.4 \pm 2.5$ & $88.5 \pm 3.7$ \\
\hline Post & $60.1 \pm 7.9^{\dagger}$ & $72.7 \pm 5.9^{\dagger \dagger \dagger}$ & $46.8 \pm 12.3^{\dagger}$ & $44.3 \pm 13.2^{\dagger}$ \\
\hline \multicolumn{5}{|c|}{ Passive diameter, $\mu \mathrm{m}$} \\
\hline Pre & $243 \pm 5$ & $227 \pm 5$ & $230 \pm 5$ & $187 \pm 3^{* * *}$ \\
\hline Post & $196 \pm 2^{\dagger \dagger \dagger}$ & $216 \pm 6^{\S \dagger}$ & $203 \pm 5^{\dagger \dagger \dagger}$ & $153 \pm 2^{* * * \dagger \dagger \dagger}$ \\
\hline \multicolumn{5}{|c|}{ Basal tone, $\%$ of passive diameter } \\
\hline Pre & $95.5 \pm 1.7$ & $98.0 \pm 0.9$ & $95.4 \pm 2.9$ & $94.8 \pm 3.3$ \\
\hline Post & $80.5 \pm 4.1^{\dagger}$ & $60.4 \pm 4.1^{\S \dagger \dagger \dagger}$ & $75.8 \pm 5.3^{\dagger \dagger}$ & $77.8 \pm 5.6^{\dagger}$ \\
\hline
\end{tabular}

Diameters were measured at $80 \mathrm{~mm} \mathrm{Hg}$ intraluminal pressure with PSS-MOPS superfusion and PSS-MOPS presence in the lumen without flow at $37^{\circ} \mathrm{C}$. PE, phenylephrine; $\%$ of passive diameter, diameter with $10^{-5} \mathrm{M} \mathrm{PE} /$ passive diameter $\times 100$; ACh, acetylcholine; \% dilation, (diameter with $10^{-5} \mathrm{M} \mathrm{ACh}$ - preconstricted diameter)/ (passive diameter - preconstricted diameter) $\times 100$; basal tone, $\%$ of passive diameter $=$ baseline diameter $/$ passive diameter $\times 100.1$ or 2 arteries in each group were measured with $10^{-6}$ or $10^{-4} \mathrm{M} .{ }^{* *} p<0.01,{ }^{* * *} p<0.001$, vs. all other groups (one-way ANOVA); ${ }^{\circledR} p<0.05$ vs. low SS (one-way ANOVA); ${ }^{\dagger} p<0.05,{ }^{\dagger \dagger} p<0.01,{ }^{\dagger \dagger \dagger} p<$ 0.001 , vs. corresponding "pre” value (paired $t$ test). For 4 arteries in the high SS group, post PE response data were missing, and for 1 artery in the high SS + L-NAME group, pre PE response data are also missing due to a very constricted baseline diameter. 
Table 3. Artery responses (mean \pm SEM) to culture $(\sim 20 \mathrm{~h})$ with luminal flow

\begin{tabular}{lcc}
\hline & $\begin{array}{l}\text { Low flow } \\
(n=5)\end{array}$ & $\begin{array}{l}\text { High flow } \\
(n=5)\end{array}$ \\
\hline $\begin{array}{l}\text { Preculture reactivity } \\
\quad \text { Baseline diameter }\end{array}$ & $149 \pm 21$ & $120 \pm 18$ \\
$\quad+$ ACh $\left(10^{-5} \mathrm{M}\right)$ & $267 \pm 11$ & $252 \pm 10$ \\
$\quad$ Dilation, $\mu \mathrm{m}$ & $118 \pm 13$ & $132 \pm 20$ \\
Postculture reactivity, $\mu \mathrm{m}$ & $137 \pm 22$ & $106 \pm 12$ \\
$\quad$ Baseline diameter & $168 \pm 27^{\dagger}$ & $183 \pm 10^{\dagger}$ \\
$\quad+$ ACh $\left(10^{-5}-10^{-4} \mathrm{M}\right)$ & $31 \pm 8^{\dagger}$ & $77 \pm 7^{* *}$ \\
$\quad$ Dilation & $82 \pm 4$ & $95 \pm 7$ \\
Initial culture diameter, $\mu \mathrm{m}$ & $65 \pm 5^{\dagger}$ & $70 \pm 8$ \\
Final culture diameter, $\mu \mathrm{m}$ & $74 \pm 4$ & $83 \pm 5$ \\
Average diameter during culture & $2.1 \pm 0.4$ & $29.9 \pm 1.7^{* * * *}$ \\
Average flow rate, $\mu \mathrm{L} / \mathrm{min}$ & $5.9 \pm 0.9$ & $69.7 \pm 14.2^{* *}$ \\
Average shear stress, dyn $/ \mathrm{cm}^{2}$ & &
\end{tabular}

These arteries were used in the gene expression analysis in Figure 5. Arteries were maintained in L15 medium + newborn calf serum (NCS) in perfusate and superfusate during culture. Pre- and postculture reactivity was measured in superfusate without NCS. ${ }_{* *} p<0.01,{ }^{* * * *} p<0.0001$, vs. low flow (Student $t$ test); ${ }^{\dagger} p<0.01$ vs. corresponding preculture value or initial culture diameter (paired Student $t$ test).

streptomycin $(10 \mathrm{IU} / \mathrm{mL}$ and $10 \mu \mathrm{g} / \mathrm{mL}$, respectively; Mediatech, Inc.), and $10 \%$ fetal bovine serum (FBS; Hyclone, Logan, UT, USA), which was sterile filtered and superfused around the artery and perfused through the lumen and maintained at room temperature $\left(19-24^{\circ} \mathrm{C}\right)$ to minimize microbial growth and optimize long-term viability and vasomotor function, as determined in pilot experiments. The lower temperature may be optimal for this artery given that it is a superficial artery. In support of this idea, another superficial artery, the gracilis muscle feed artery, has been successfully cultured at room temperature [42]. The introduction of medium caused vasoconstriction to $\sim 50 \%$ of the baseline diameter in all arteries, which continued throughout the culture period. Superfusion medium was recirculated from a $100-\mathrm{mL}$ reservoir and was refreshed after $\sim 24 \mathrm{~h}$. Flow through the lumen was controlled by gravity. Inflow and outflow reservoirs (large reservoirs were used to minimize changes in the pressure gradient with chronic flow) were raised to $109 \mathrm{~cm} \mathrm{H}_{2} \mathrm{O}$ (equivalent to $80 \mathrm{~mm} \mathrm{Hg}$ ), and flow was initiated by raising the inflow reservoir and lowering the outflow reservoir equal distances. Because the cannula resistances were matched, the average pressure would be maintained at $80 \mathrm{~mm}$ Hg. A microflowmeter (model GF-3060; Gilmont Instruments, Barrington, IL, USA) was placed between the outflow cannula and the outflow reservoir. Flow was set to produce $S S<5 \mathrm{dyn} / \mathrm{cm}^{2}$ (low $\mathrm{SS}$ group) or $>15 \mathrm{dyn} / \mathrm{cm}^{2}$ (high SS groups). SS (dyn $/ \mathrm{cm}^{2}$ ) was calculated by: $4 \times$ viscosity $\times$ flow $\times 10^{9} / \pi \times$ radius $^{3}$; with viscosity $=$ $0.007 \mathrm{dyn} \times \mathrm{s} / \mathrm{cm}^{2}$, flow in $\mu \mathrm{L} / \mathrm{s}$, the $10^{9}$ factor to correct for using $\mu \mathrm{L} / \mathrm{s}$ for flow $\left(1 \mu \mathrm{L}=10^{9} \mu \mathrm{m}^{3}\right)$, and radius in $\mu \mathrm{m}$. The pressure gradient set to achieve the desired SS at the beginning of the experiment (based on the initial artery diameter in the presence of culture medium) was maintained throughout the rest of the culture period. High SS generally produced an acute dilation, but this was very transient and not routinely measured. The initial culture diameter was measured after a steady state diameter was reached ( $>5$ min after initiation of flow). The flow and artery diameter (in the presence of culture medium) were recorded daily (at 0,24, and $48 \mathrm{~h}$ ), and the average value was used to calculate the average SS over the culture period (Table 1). Flow rates over the first and second $24-\mathrm{h}$ periods were similar (Table 1 ) and at a level to maintain the desired SS range. The average physiological SS in an artery of this size is estimated to be between 10 and $55 \mathrm{dyn} / \mathrm{cm}^{2}[43,44]$. Average SS over the culture period was significantly greater in all the high SS groups than the low SS group when compared by Student $t$ test (Table 1), but only in the high SS eNOS-/- when compared by ANOVA. However, average SS levels remained in the target ranges for each treatment over the culture period.

At the end of the 2-day culture period, the chamber and artery lumen were flushed with MOPS-buffered PSS at $37^{\circ} \mathrm{C}$, and equilibrated for at least $30 \mathrm{~min}$ with luminal pressure of $80 \mathrm{~mm} \mathrm{Hg}$ generated by a pressure manometer without luminal flow. Responses to $\mathrm{PE}\left(10^{-5} \mathrm{M}\right)$ and $\mathrm{ACh}\left(10^{-5} \mathrm{M}\right)$ were again measured, and maximal diameter was measured either in the presence of sodium nitroprusside (SNP; $10^{-4} \mathrm{M}$ ) or $\mathrm{Ca}^{2+}$-free MOPS-buffered PSS with EGTA (1 mM). The change from SNP to $\mathrm{Ca}^{2+}$-free PSS occurred half-way through the project with the rationale that it might more fully relax the arteries; however, we found no significant differences within any of the groups in final passive or percent change in passive diameter with the different methods of measuring final passive diameter so the data with the different methods are combined (data not shown).

Many arteries began the culture protocol ( 89 arteries), but were discarded for technical or viability reasons (57 arteries). The technical issues included were clogs that developed in the perfusion line that stopped flow (most common in the high SS group), arteries leaking or dislodging from the cannula, and chamber leaks. In addition, arteries that did not respond to $\mathrm{PE}$ at the beginning or end of the culture period were considered dead and were discarded. Arteries were typically very constricted during culture, but some spontaneously dilated sometime during culture. We found that these arteries did not respond to PE, indicating loss of viability. The arteries used in analyses (32 arteries) originated from mice that were $14.6 \pm 0.5$ weeks old (range $7-25$ weeks). Ages (mean \pm SEM) of the mice were similar in each group (in weeks: low SS = $17.3 \pm 2.0$, high SS $=16.1 \pm 1.5$, high SS + L-NAME = 15.4 \pm 1.8 ), with the exception of slightly younger mice in the high SS eNOS-/group $(9.8 \pm 1.0 ; p<0.05$ compared to low SS and high SS).

\section{Part 2: Gene Expression with Differential SS in Cultured}

\section{Arteries}

Female C57BL/6 mice (Charles River Laboratories, Inc., Wilmington, MA, USA) were housed in standard cages in climatecontrolled, 12-h light/12-h dark environment, with free access to food and water, and used in the experiment at $19.0 \pm 1.0$ weeks of age (range 10.4-22.0 weeks). The treatment groups were low and high SS, with no difference in the average ages of mice used in the 2 groups (low SS: $20.4 \pm 0.4$ weeks, high SS: $17.7 \pm 1.9$ ).

Arteries were cultured as described in part 1, with some differences. Mice were anesthetized with sodium pentobarbital (Nembutal, $50 \mathrm{mg} / \mathrm{kg}$ body weight, i.p.). Arteries were initially cannulated with superfusion of L15 medium (with L-glutamine and penicillin/ streptomycin as in part 1) without serum and perfusion of L15 me- 
dium with serum (newborn calf serum; HyClone). Serum was omitted from the superfusate only during reactivity measurements before and after culture to reduce the amount of preconstriction, which is near maximal when included, but then added before inducing flow and undergoing culture. After initial equilibration of the artery in serum-free culture medium, which induced $\sim 50 \%$ constriction, peak response to $10^{-5} \mathrm{M} \mathrm{ACh}$ (3-5 min after addition) was measured to ensure endothelial viability. The artery chamber was then flushed with fresh medium containing serum and allowed to equilibrate to the smaller diameter ( $\sim 65 \%$ constriction). Luminal flow was then increased to either (1) induce low SS $\left(<10 \mathrm{dyn} / \mathrm{cm}^{2}\right.$ based on the diameter immediately before flow; generally $<10 \mu \mathrm{L} / \mathrm{min}$ flow), or (2) high SS ( $>20 \mathrm{dyn} / \mathrm{cm}^{2}$; generally $<20 \mu \mathrm{L} / \mathrm{min}$ flow). After equilibration $(\sim 20 \mathrm{~min})$, preculture diameter was measured, and the artery was cultured $\sim 20 \mathrm{~h}(19.8 \pm 3.2 \mathrm{~h})$ with $100 \mathrm{~mL}$ of recirculating medium with serum. Postculture diameter and total flow were then measured, and the artery was flushed with medium without serum to measure postculture ACh reactivity $\left(10^{-5} \mathrm{M}\right.$ followed by $10^{-4} \mathrm{M}$ $\mathrm{ACh}$ in all arteries except 1 from each group that showed a robust response with $10^{-5} \mathrm{M}$ ). Arteries were then immediately placed in RNAlater and stored at $-80^{\circ} \mathrm{C}$ to preserve mRNA.

RNA was isolated using the RNeasy fibrous tissue MiniKit (Qiagen, Valencia, CA, USA), and real-time PCR was performed at the Nucleic Acids Research Facilities at Virginia Commonwealth University using TaqMan one-step RT-PCR Master Mix reagent kit (Applied Biosystems). Samples were tested in triplicate with the following cycling conditions: $48^{\circ} \mathrm{C}$ for $30 \mathrm{~min}, 95^{\circ} \mathrm{C}$ for $10 \mathrm{~min}$, and $40 \mathrm{cycles}$ at $95^{\circ} \mathrm{C}$ for $15 \mathrm{~s}$ and at $60^{\circ} \mathrm{C}$ for $1 \mathrm{~min}$. Expression was quantified with a relative standard curve generated with control mouse aorta RNA. Primers and TaqMan probes for eNOS, Cx37, Cx40, Cx43, and smooth muscle a-actin (SMAA) were previously published [45], except for PECAM-1 (accession No. NM_008816; forward primer: GGCACACCTGTAGCCAACTTC, reverse primer: CGGCGATCTTGCTGAAATTC, TaqMan probe: ACTGCGACAAGACCGTCTCTTCCT). No significant genomic DNA contamination was detected, and optimal assay efficiency was observed. mRNA expression for each gene (eNOS, Cx37, Cx40, and Cx43) was normalized to PECAM-1 mRNA to control for relative endothelial content and SMAA mRNA expression to control for relative smooth muscle content.

\section{Statistical Analysis}

Comparisons between groups were performed using one-way ANOVA, or two-way repeated-measure ANOVA when before versus after comparisons were made, both with Bonferroni's post hoc analysis (Prism 4; GraphPad Software, Inc., San Diego, CA, USA). Artery parameters between 2 treatment groups were compared by two-tailed, Student $t$ test, and within each group levels before and after culture were compared by two-tailed, paired Student $t$ test (Excel; Microsoft, Redmond, WA, USA). Each figure and table indicates the specific statistical test used.

\section{Results}

\section{Part 1: Remodeling Response to SS and Contribution} of eNOS

Baseline diameters (diameter after 30 min of equilibration in MOPS-buffered PSS) and passive diameters were

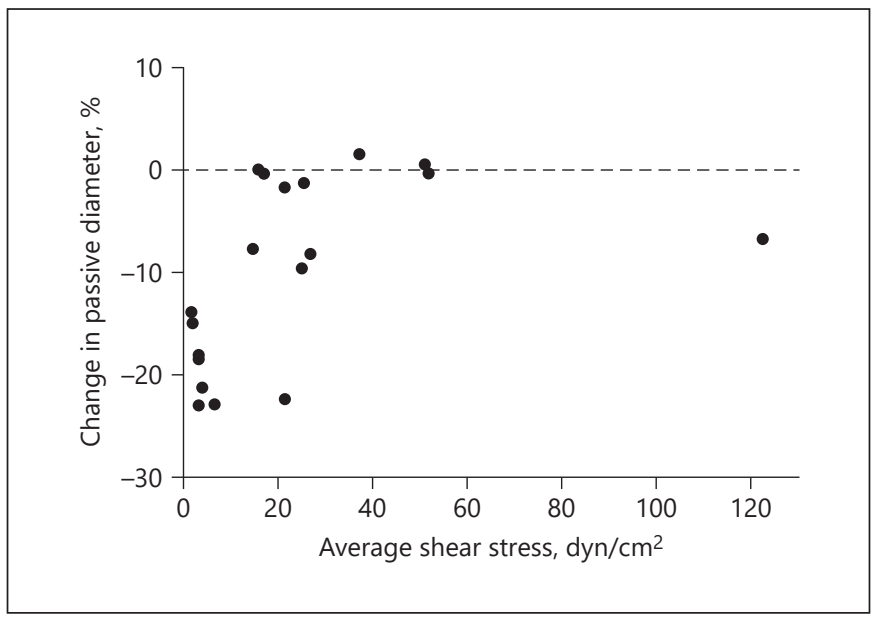

Fig. 1. Greater luminal shear stress prevents inward remodeling (change in passive diameter) in mouse thoracodorsal arteries cultured for 2 days. Passive diameter was measured at $80 \mathrm{~mm} \mathrm{Hg} \mathrm{lu-}$ minal pressure before culture in MOPS-buffered PSS with addition of papaverine $\left(10^{-4} \mathrm{M}\right)$ and after culture with SNP $\left(10^{-4} \mathrm{M}\right)$ or $\mathrm{Ca}^{2+}$-free MOPS-buffered PSS with EGTA (1 mM). Artery reactivity of each treatment group is shown in Table 2 and culture parameters are shown in Table 1 (first 2 treatment columns in each table).

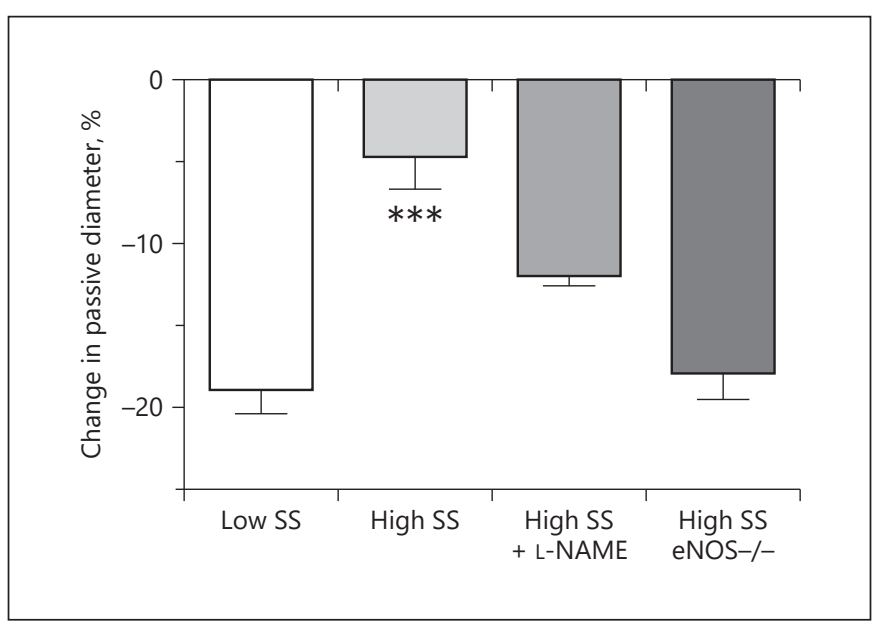

Fig. 2. The magnitude of inward remodeling (mean \pm SEM) in 2-day-cultured arteries is determined by the levels of luminal shear stress (SS) and presence of nitric oxide and eNOS. Artery reactivity of each treatment group is shown in Table 2 and culture parameters are shown in Table $1 .{ }^{* * *} p<0.001$ vs. low SS and high SS eNOS-/- (one-way ANOVA with Bonferroni post hoc tests).

similar before culture, indicating that there was no significant myogenic (basal) tone in thoracodorsal arteries in any group (Table 2), consistent with a previous study of this artery [27]. However, after culture, baseline diam- 

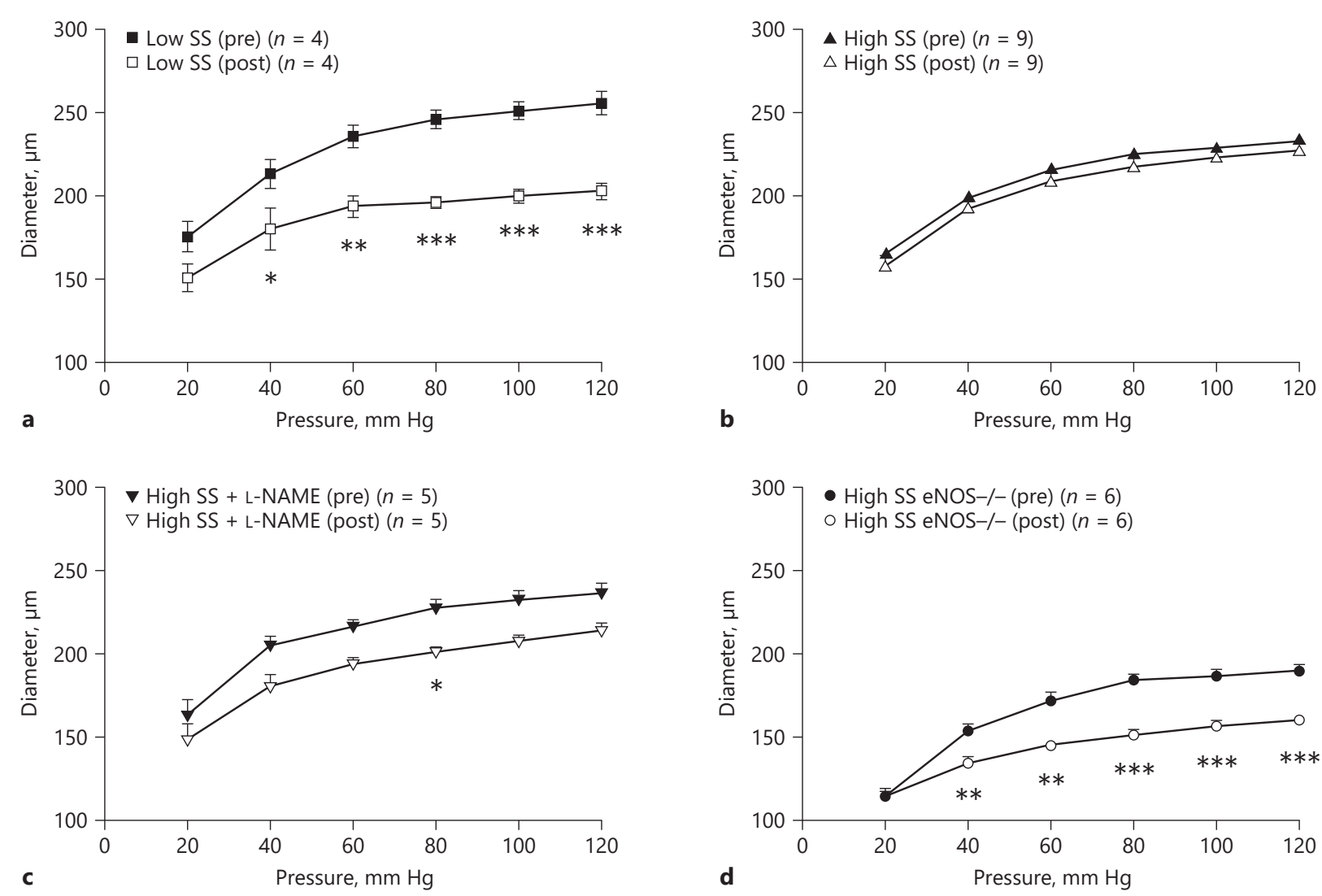

Fig. 3. Passive diameters (mean \pm SEM) are smaller after (post) than before culture (pre) in low shear stress (SS), high SS + L-NAME, or high SS eNOS-/- groups at various pressures. There were no differences in pre- vs. postculture diameters in the high SS group at any pressure. Pressures were increased stepwise in $\sim 5$-min intervals. ${ }^{*} p<0.05,{ }^{* *} p<0.01,{ }^{* * *} p<0.001$, vs. preculture passive diameter (two-way repeated-measure ANOVA with Bonferroni post hoc tests).

eters were significantly smaller than passive diameters in all groups, indicating significant basal tone (Table 2) or perhaps a residual effect of the culture medium after washout. Also, arteries from eNOS-/- mice were significantly smaller than arteries from wild-type mice (Table 2). After culture, arteries constricted similarly to PE as they did before culture (Table 2). Dilation responses to ACh were more variable within a group and were significantly reduced in all groups after culture (Table 2). There were, however, no significant differences in ACh responses between groups before or after culture.

After culture, passive diameters were reduced in arteries with low luminal SS, indicating inward remodeling (Fig. 1). The magnitude of this remodeling is similar to that found in a previous study of cultured rat cremaster arterioles with low flow [22]. Increased SS prevented this remodeling, and this attenuation was most pronounced with SS $>15 \mathrm{dyn} / \mathrm{cm}^{2}$ (Fig. 1), the predicted physiological SS $[43,44]$. When artery responses were grouped by SS, the magnitude of inward remodeling after culture was significantly greater in the low SS group (SS $<7 \mathrm{dyn} / \mathrm{cm}^{2}$ ) than the high SS group (SS $>15 \mathrm{dyn} / \mathrm{cm}^{2}$ ), which had minimal remodeling (Fig. 2). Chronic inhibition of NOS with L-NAME resulted in inward remodeling despite elevated SS (high SS + L-NAME group; Fig. 2). Similarly, absence of eNOS in knockout mice also resulted in inward remodeling despite elevated SS (high SS eNOS-/- group; Fig. 2), which was significantly greater than high SS. The differences in passive diameters before and after culture with stepped increases in pressure, measured in most but not all vessels, showed similar differences as observed at 80 $\mathrm{mm} \mathrm{Hg}$ (Fig. 3). Significantly smaller postculture passive 


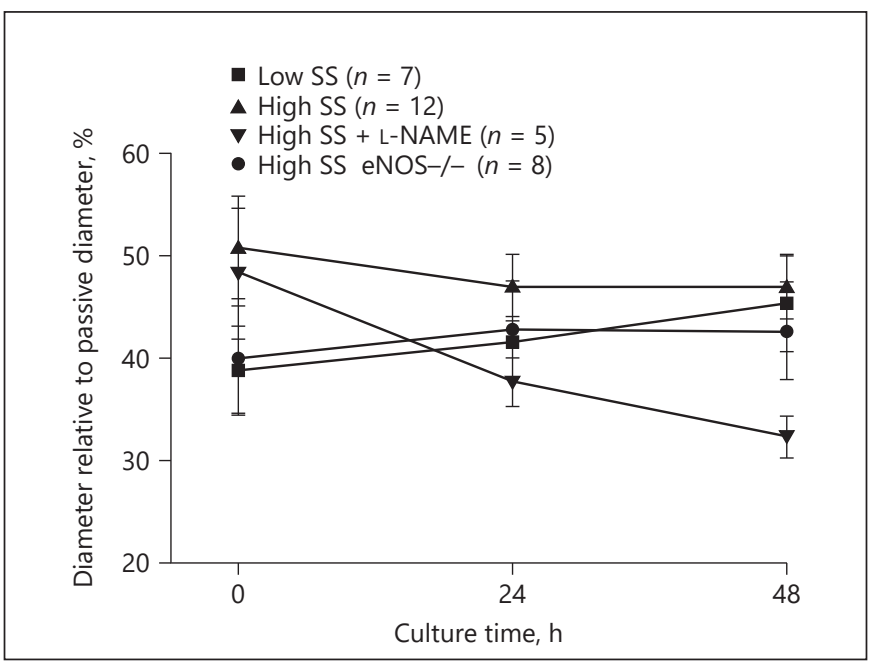

Fig. 4. The levels of shear stress (SS) do not regulate the magnitude of constriction (mean \pm SEM) during 2-day culture. Arteries were then cultured at $80 \mathrm{~mm} \mathrm{Hg}$ luminal pressure in Lebovitz medium + FCS for 2 days. Arteries stably constricted $(y$ axis [\%] $=$ culture diameter/initial passive diameter $\times 100)$ in the presence of culture medium throughout the culture period with no differences between the groups. Artery reactivity of each treatment group is shown in Table 2, and culture parameters are shown in Table 1.

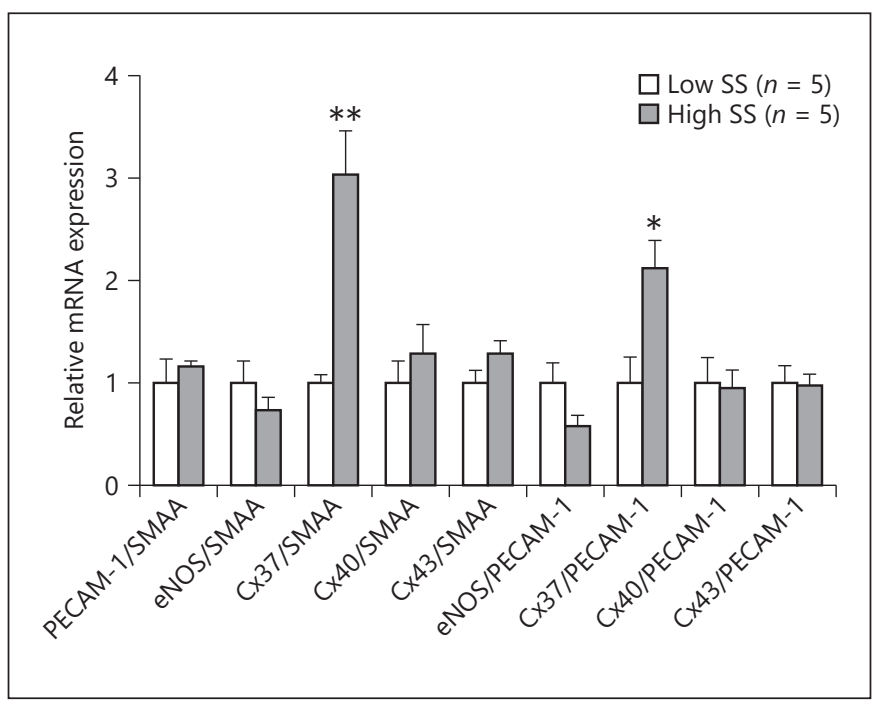

Fig. 5. Relative mRNA expression normalized to mRNA of smooth muscle cell marker (SMAA) or endothelial cell marker (PECAM-1) in arteries cultured for 1 day with low or high luminal shear stress (SS). Ratios (mean \pm SEM) are expressed relative to the average value for the low SS group. ${ }^{*} p<0.05,{ }^{* *} p<0.01$, vs. low SS (twotailed Student $t$ test). Artery reactivity in each treatment group is shown in Table 3.

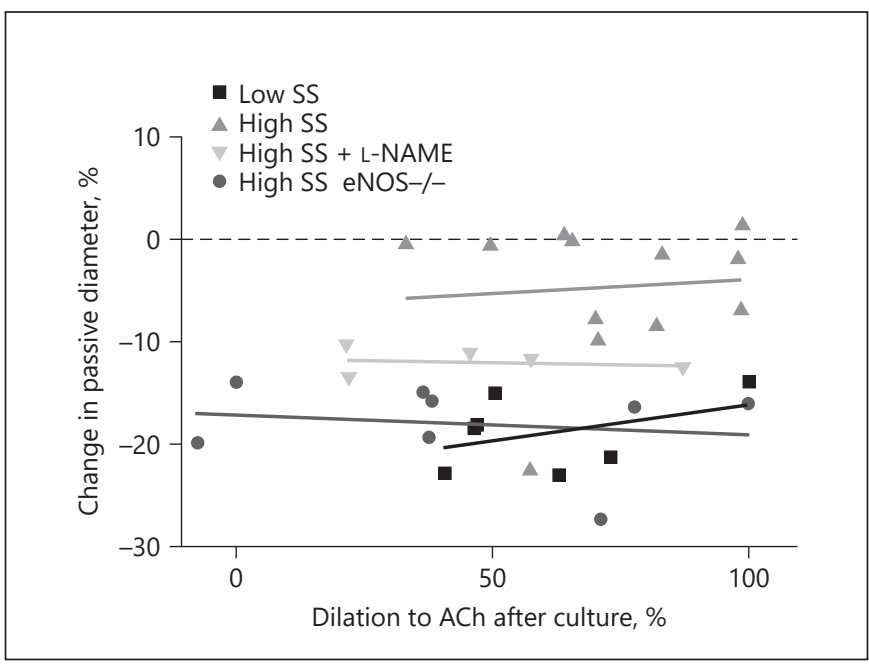

Fig. 6. Responsiveness to acetylcholine (ACh) at the end of 2-day culture is not correlated with the magnitude of inward remodeling. Arteries from each treatment group displayed a range of reactivity to $\mathrm{ACh}$ at the end of culture ( $x$-axis) that did not correlate with the magnitude of remodeling ( $y$-axis). Linear regression lines shown for each treatment group are not significant.

diameters were observed in low SS and high SS eNOS-/groups at all pressures except $20 \mathrm{~mm} \mathrm{Hg}$, and there were no differences in postculture diameters in high SS groups. The magnitude of inward remodeling in the high SS + L-NAME group was not significantly different from the high SS group (Fig. 2), and a significantly smaller postculture diameter was only observed at $80 \mathrm{~mm} \mathrm{Hg}$ (Fig. 3).

Arteries in all groups immediately constricted in response to addition of culture medium and remained constricted throughout the culture period (Fig. 4), with a similar average daily magnitude of constriction (Fig. 4) and similar overall average constriction magnitudes ( $\%$ of preculture passive diameter) over the entire culture period (Table 1).

Within the wild-type treatment groups, most of the mice were chimeric C57BL6/129 mice (low SS: 5/7 mice, high SS: 8/12, high SS + L-NAME: $3 / 5$ ) with some C57BL6 mice. There were no differences in passive diameter, remodeling response, $\mathrm{PE}$ and $\mathrm{ACh}$ reactivity, or average culture diameter between these strains within each treatment group ( $t$ tests; data not shown).

\section{Part 2: Gene Expression with Differential SS in Cultured Arteries}

Before culture, artery constriction to culture medium (without serum) and subsequent dilation to ACh were 
similar between low and high SS groups. However, low SS arteries constricted significantly by the end of the culture period (final culture diameter compared to initial culture diameter) and exhibited a smaller postculture dilation response to ACh compared to the high SS arteries (Table 3). Both groups dilated to a smaller final diameter with ACh after culture (Table 3 ). These functional responses show a pattern similar to those in part 1. PECAM-1 mRNA was similar between groups when normalized to the smooth muscle cell marker SMAA, indicating similar endothelial cell content between groups (Fig. 5). Because constriction responses during the postculture reactivity test were similar, it is logical to conclude that smooth muscle cell content is similar between the groups, and, therefore, SMAA is a valid normalizing gene. eNOS, $\mathrm{Cx} 40$, and $\mathrm{Cx} 43 \mathrm{mRNA}$ levels were similar between groups whether normalized to SMAA or PECAM-1 (Fig. 5). However, Cx37 mRNA expression was significantly greater in the high SS group whether normalized to SMAA or PECAM-1 (Fig. 5).

\section{Discussion}

This study shows that SS in the physiological range can nearly eliminate inward remodeling in pressurized, cultured mouse small arteries. eNOS is shown to be essential to this process, and increased $\mathrm{Cx} 37$ was coincident. This finding extends those of Pistea et al. [26] indicating involvement of $\mathrm{NO}$ in the ability of SS to counter inward remodeling in culture, with some differences between the studies. Their porcine coronary arteries treated with high flow were relatively dilated (i.e., had less constriction) during culture, and addition of L-NAME did not prevent this dilation but did prevent flow-induced attenuation of inward remodeling. So, while our study did not demonstrate a sustained vasomotor effect of flow as theirs did, both studies indicate that vasodilation is not necessarily coupled to flow-induced prevention of inward remodeling. It is also notable that while the ACh-induced vasodilation in the mouse thoracodorsal arteries used in the present study is only $\sim 50 \%$ dependent on NO (the remainder due to cyclooxygenase and endothelial-dependent hyperpolarization) [27], we found that the shear-induced prevention of remodeling is largely NO and eNOS dependent.

The most important contribution of the present study is the use of eNOS-/- mice because it specifically tests the involvement of one of the NOS isoforms. This is important given that there is evidence that $\mathrm{nNOS}$ and iNOS are also involved in remodeling in vivo [46-50]. It also offers

eNOS-Dependent SS Remodeling and Increased Cx37 Expression a technical advantage because it avoids nonspecific effects of NOS inhibitors [51-53] or incomplete inhibition. Based on the data in the present study, we can conclude that eNOS is essential to SS-induced prevention of inward remodeling in cultured arteries. This approach allows for control of hemodynamic parameters and vasoactive agonists and assessment of their effects on remodeling without the influence of neurohumoral factors. However, the role of eNOS in SS-induced remodeling in vivo is likely to be more complex, as suggested by evidence from eNOS-/- mice. These mice exhibit the expected attenuated outward remodeling to high flow $[54,55]$. However, the response to low flow is more complicated, with evidence for paradoxically reduced inward remodeling in some vessels $[13,54,56]$, increased inward remodeling in others [49], and exaggerated neointima formation in large arteries $[13,49]$. In vivo, recruited bone marrowderived cells expressing various NOS isoforms are involved in suppression of inward remodeling after carotid ligation [48]. Thus, the use of eNOS-/- arteries in culture in this study eliminates these systemic factors and identifies the ability of resident eNOS in endothelium to counter inward remodeling processes intrinsic to the vessel.

$\mathrm{NO}$ is well known to be involved in remodeling responses to flow $[14,15,57]$, but it has not been clear whether the effects of NO occur via regulation of vasomotor tone or cellular growth/remodeling processes. Our results argue against a vasomotor role for $\mathrm{NO}$ (given that artery diameters were similar at different SS) and support the idea that NO regulates remodeling. Inward remodeling of small arteries is likely to involve remodeling of the extracellular matrix and smooth muscle cell cytoskeletal structure and contacts $[8,58,59]$. An important mediator in the acute phase of inward remodeling has been found to be the cross-linking enzyme, tissue-type transglutaminase (tTG, or TG2) [60]. In vivo, pharmacological inhibition or genetic knockout of tTG delays low-flow inward remodeling $[61,62]$, and pharmacological inhibition eliminates vasoconstrictor-induced inward remodeling [11]. In cultured arteries, inhibition of $\mathrm{tTG}$ eliminates inward remodeling without inhibiting constriction [62]. This enzyme is of particular relevance to the present study because it is inhibited by NO $[63,64]$. Thus, the likely increase in NO with high SS may have prevented the action of $\mathrm{tTG}$, and, therefore, the inward remodeling. This mechanism would need to be specifically tested.

With 1-day culture, we found an increase in $\mathrm{Cx} 37$ without change in the other genes examined. Cx37 is primarily expressed in endothelial cells [65], and the in- 
crease in Cx37 is in line with a majority of the findings in cultured cells and in vivo. In cultured endothelial cells, Cx37 has been reported to increase in response to high SS (5-25 dyn $/ \mathrm{cm}^{2}, 30$-min to 24 -h treatment) versus static flow in many studies $[37,40,66,67]$ but not all [68-70]. One of these studies found that $\mathrm{Cx} 37$ was increased when cocultured with smooth muscle cells [68], but other studies did not $[66,70]$. Elevating SS from normal levels (15$\left.20 \mathrm{dyn} / \mathrm{cm}^{2}\right)$ to very high levels $\left(75-100 \mathrm{dyn} / \mathrm{cm}^{2}\right)$ in cultured endothelial cells $(24 \mathrm{~h})$ has not been shown to increase Cx37 [71]. In vivo, Cx37 is more prominently expressed in arterial endothelial cells in areas of high SS [37], in developing/remodeling arteries [40], and in arterial smooth muscle (where it is not normally expressed) during collateral growth [72], but it is decreased in areas of disturbed flow [37]. The present study shows that Cx37 also increases in cultured arteries exposed to high SS without exposure to in vivo neurohumoral factors, indicating that the hemodynamic factors are sufficient for, or at least participate in, the increase. It is not clear what the role of the increased $\mathrm{Cx} 37$ is in this study, but in vivo studies indicate that endothelial Cx37 expression is involved in flow-induced endothelial cell arrest and limiting angiogenesis and blood flow recovery during ischemic occlusion $[35,36]$.

We found no change in $\mathrm{Cx} 40$ or $\mathrm{Cx} 43$ mRNA expression after 1-day treatment with SS. This is not surprising given that the role of these connexins in mechanotransduction and remodeling is unclear. Cx40 is expressed in endothelial cells [65], but its response to SS in cultured endothelial cells is variable $[39,68,70,73]$, and in vivo its expression does not seem to be affected by chronic variations in SS in large arteries $[37,74]$. While its role in SSinduced remodeling is unclear, it is reported to have a protective role against atherosclerotic remodeling with low SS [39]. Cx43 is expressed in endothelial and smooth muscle cells [65]. It increases in cultured endothelial cells in response to changes in SS, both laminar and oscillatory, but the increase appears to be very transient, except with oscillatory SS [68, 70, 75-79]. In vivo, greater Cx43 is expressed in aortic endothelium in areas of disturbed flow [74]. Our results indicate no effect of SS on Cx43 at $20 \mathrm{~h}$ of culture, but this does not rule out a transient early change.

The lack of change in eNOS with high SS is not entirely unexpected given evidence from other studies. It is well established that SS acutely (3-24 h) increases eNOS mRNA expression in cultured endothelial cells [28-33]. However, evidence in isolated arteries indicates both increase [80] or no change [81] in eNOS mRNA with acute
(2-4 h) SS, and evidence in vivo indicates that $24 \mathrm{~h}$ of either high or low SS decreases eNOS mRNA in rat mesenteric arteries [82]. The lack of change in our experiments may be due to the chronic constriction caused by the serum added to the culture medium, as a previous study found that attenuating this constriction with a ROCK inhibitor prevented the decrease in eNOS mRNA that occurred at 7 days of culture with FBS [83].

\section{Limitations}

A limitation of this study is that endothelial integrity at the end of the culture period was not confirmed by a measure other than the ACh response, which was variable between arteries. Postculture ACh response significantly decreased in both 1- and 2-day-cultured arteries and similarly across the groups. This is not unexpected. Loss of agonist-induced endothelial-dependent vasodilation is a common finding in chronically constricted arteries in culture, even with a confirmed intact endothelium (by electron microscopy) $[22,23,26]$, and it is not dependent on whether there is luminal flow in the artery [26]. It is unlikely that the decline in the ACh response in the present study affected the remodeling response because there was no correlation between these 2 parameters in any of the groups (Fig. 6). Moreover, neither PECAM-1 nor eNOS expression were different between high and low SS groups, suggesting that endothelial cell content was similar between the groups on day 1 . Therefore, with similar ACh responses after 1 and 2 days, it is likely that a decreased ACh response does not indicate endothelial cell loss but may instead be a long-term effect of the chronic constriction and/or culture conditions. Even if there was some endothelial cell loss in some arteries over the course of the culture, it may not affect the remodeling response because there is evidence that inward remodeling can occur as early as the first $4 \mathrm{~h}$ of culture during chronic constriction $[24,84]$.

This study did not specifically test the effects of low flow on remodeling with NOS inhibition or eNOS knockout for 2 reasons. The previous study by Pistea et al. [26] showed that low and high flow with NOS inhibition produced the same amount of inward remodeling and was also similar to low flow alone. In addition, we saw no differences in culture diameters in the NOS inhibition or eNOS knockout groups to suggest that there would be enhanced remodeling beyond the low SS group. Therefore, these experiments did not seem to be critical, but could have provided additional confirmatory data. Notably, the magnitude of inward remodeling with L-NAME was not as great as in the eNOS-/- group and only ob- 
served at $80 \mathrm{~mm} \mathrm{Hg}$. This might indicate that L-NAME did not completely block NO production.

Another potential limitation is the difference in age between the groups in part 1 of the study. High SS eNOS-/- mice were slightly younger than 2 of the other groups. However, all mice were at the same life stage, mature adults and pre-middle age for this strain (C57B16), and, therefore, all were expected to be at an age of peak physiological function [85].

\section{Summary and Conclusions}

SS in the physiological range prevents inward remodeling in cultured arteries due to chronic constriction through an NO-, and specifically an eNOS-dependent, mechanism. The effects of SS require NO but do not require vasodilation. Thus, NO induced by SS prevents inward remodeling independent of changes in artery diameter. While eNOS expression is not acutely changed in response to flow in culture, the increase in $\mathrm{Cx} 37$ expression indicates that it is responsive to increased SS under these conditions.

\section{Acknowledgments}

This work was funded by R35 HL139945, the Merit Award of the American Heart Association, PO1 HL107205 (W.C.S); F32HL67626 and 1-R15-HL082647-01 (R.C.L.-W.); and the Howard Hughes Medical Institute grant through the Undergraduate Biological Sciences Education Program to the College of William and Mary (J.E.B.).

\section{Statement of Ethics}

All procedures in part 1 were approved by the Yale Animal Care and Use Committee. All procedures in part 2 were approved by the William and Mary Institutional Animal Care and Use Committee and were in accordance with the Guide for the Care and Use of Laboratory Animals (National Research Council).

\section{Disclosure Statement}

The authors have no conflicts of interest to report.

\section{References}

1 Ben Driss A, Benessiano J, Poitevin P, Levy BI, Michel JB. Arterial expansive remodeling induced by high flow rates. Am J Physiol. 1997 Feb;272(2 Pt 2):H851-8.

2 Kamiya A, Togawa T. Adaptive regulation of wall shear stress to flow change in the canine carotid artery. Am J Physiol. 1980 Jul;239 (1):H14-21.

3 Langille BL, O'Donnell F. Reductions in arterial diameter produced by chronic decreases in blood flow are endothelium-dependent. Science. 1986 Jan;231(4736):405-7.

4 Tulis DA, Unthank JL, Prewitt RL. Flow-induced arterial remodeling in rat mesenteric vasculature. Am J Physiol. 1998 Mar;274 (3):H874-82.

5 Tuttle JL, Nachreiner RD, Bhuller AS, Condict KW, Connors BA, Herring BP, et al. Shear level influences resistance artery remodeling: wall dimensions, cell density, and eNOS expression. Am J Physiol Heart Circ Physiol. 2001 Sep;281(3):H1380-9.

6 Unthank JL, Fath SW, Burkhart HM, Miller SC, Dalsing MC. Wall remodeling during luminal expansion of mesenteric arterial collaterals in the rat. Circ Res. 1996 Nov;79(5): 1015-23.

7 Langille BL, Bendeck MP, Keeley FW. Adaptations of carotid arteries of young and mature rabbits to reduced carotid blood flow. Am J Physiol. 1989 Apr;256(4 Pt 2):H931-9.
8 Castorena-Gonzalez JA, Staiculescu MC, Foote C, Martinez-Lemus LA. Mechanisms of the inward remodeling process in resistance vessels: is the actin cytoskeleton involved? Microcirculation. 2014 Apr;21(3):219-29.

9 Mulvany MJ. Small artery remodelling in hypertension. Basic Clin Pharmacol Toxicol. 2012 Jan;110(1):49-55.

10 Schiffrin EL. Mechanisms of remodelling of small arteries, antihypertensive therapy and the immune system in hypertension. 2015 Dec 4;38(6):E394-402.

11 Eftekhari A, Rahman A, Schaebel LH, Chen $\mathrm{H}$, Rasmussen CV, Aalkjaer C, et al. Chronic cystamine treatment inhibits small artery remodelling in rats. J Vasc Res. 2007;44(6):47182.

12 Koller A, Sun D, Huang A, Kaley G. Corelease of nitric oxide and prostaglandins mediates flow-dependent dilation of rat gracilis muscle arterioles. Am J Physiol. 1994 Jul;267(1 Pt 2):H326-32.

13 Rudic RD, Shesely EG, Maeda N, Smithies O, Segal SS, Sessa WC. Direct evidence for the importance of endothelium-derived nitric oxide in vascular remodeling. J Clin Invest. 1998 Feb;101(4):731-6.

14 Tronc F, Wassef M, Esposito B, Henrion D, Glagov S, Tedgui A. Role of NO in flow-induced remodeling of the rabbit common carotid artery. Arterioscler Thromb Vasc Biol. 1996 Oct;16(10):1256-62.
15 Guzman RJ, Abe K, Zarins CK. Flow-induced arterial enlargement is inhibited by suppression of nitric oxide synthase activity in vivo. Surgery. 1997 Aug;122(2):273-9; discussion 279-80.

16 Ceiler DL, De Mey JG. Chronic N(G)-nitro$\mathrm{L}$-arginine methyl ester treatment does not prevent flow-induced remodeling in mesenteric feed arteries and arcading arterioles. Arterioscler Thromb Vasc Biol. 2000 Sep;20(9): 2057-63.

17 Mees B, Wagner S, Ninci E, Tribulova S, Martin S, van Haperen R, et al. Endothelial nitric oxide synthase activity is essential for vasodilation during blood flow recovery but not for arteriogenesis. Arterioscler Thromb Vasc Biol. 2007 Sep;27(9):1926-33.

18 Mooradian DL, Hutsell TC, Keefer LK. Nitric oxide (NO) donor molecules: effect of NO release rate on vascular smooth muscle cell proliferation in vitro. J Cardiovasc Pharmacol. 1995 Apr;25(4):674-8.

19 RayChaudhury A, Frischer H, Malik AB. Inhibition of endothelial cell proliferation and bFGF-induced phenotypic modulation by nitric oxide. J Cell Biochem. 1996 Nov;63(2): $125-34$. 
20 Sato J, Nair K, Hiddinga J, Eberhardt NL, Fitzpatrick LA, Katusic ZS, et al. eNOS gene transfer to vascular smooth muscle cells inhibits cell proliferation via upregulation of p27 and p21 and not apoptosis. Cardiovasc Res. 2000 Sep;47(4):697-706.

21 Yu SM, Hung LM, Lin CC. cGMP-elevating agents suppress proliferation of vascular smooth muscle cells by inhibiting the activation of epidermal growth factor signaling pathway. Circulation. 1997 Mar;95(5):1269-77.

22 Bakker EN, van Der Meulen ET, Spaan JA, VanBavel E. Organoid culture of cannulated rat resistance arteries: effect of serum factors on vasoactivity and remodeling. Am J Physiol Heart Circ Physiol. 2000 Apr;278(4):H123340.

23 Bakker EN, van der Meulen ET, van den Berg BM, Everts V, Spaan JA, VanBavel E. Inward remodeling follows chronic vasoconstriction in isolated resistance arteries. J Vasc Res. 2002 Jan-Feb;39(1):12-20.

24 Martinez-Lemus LA. Persistent agonist-induced vasoconstriction is not required for angiotensin II to mediate inward remodeling of isolated arterioles with myogenic tone. J Vasc Res. 2008;45(3):211-21.

25 Bakker EN, Buus CL, VanBavel E, Mulvany MJ. Activation of resistance arteries with endothelin-1: from vasoconstriction to functional adaptation and remodeling. J Vasc Res. 2004 Mar-Apr;41(2):174-82.

26 Pistea A, Bakker EN, Spaan JA, VanBavel E. Flow inhibits inward remodeling in cannulated porcine small coronary arteries. Am J Physiol Heart Circ Physiol. 2005 Dec;289 (6): $\mathrm{H} 2632-40$.

27 Billaud M, Lohman AW, Straub AC, Parpaite T, Johnstone SR, Isakson BE. Characterization of the thoracodorsal artery: morphology and reactivity. Microcirculation. 2012 May; 19(4):360-72.

28 Ranjan V, Xiao Z, Diamond SL. Constitutive NOS expression in cultured endothelial cells is elevated by fluid shear stress. Am J Physiol. 1995 Aug;269(2 Pt 2):H550-5.

29 Nishida K, Harrison DG, Navas JP, Fisher AA, Dockery SP, Uematsu M, et al. Molecular cloning and characterization of the constitutive bovine aortic endothelial cell nitric oxide synthase. J Clin Invest. 1992 Nov;90(5): 2092-6.

30 Uematsu M, Ohara Y, Navas JP, Nishida K, Murphy TJ, Alexander RW, et al. Regulation of endothelial cell nitric oxide synthase mRNA expression by shear stress. Am J Physiol. 1995 Dec;269(6 Pt 1):C1371-8.

31 Ohura N, Yamamoto K, Ichioka S, Sokabe T, Nakatsuka H, Baba A, et al. Global analysis of shear stress-responsive genes in vascular endothelial cells. J Atheroscler Thromb. 2003; 10(5):304-13.

32 Xiao Z, Zhang Z, Ranjan V, Diamond SL. Shear stress induction of the endothelial nitric oxide synthase gene is calcium-dependent but not calcium-activated. J Cell Physiol. 1997 May;171(2):205-11.
33 Malek AM, Jiang L, Lee I, Sessa WC, Izumo S, Alper SL. Induction of nitric oxide synthase mRNA by shear stress requires intracellular calcium and G-protein signals and is modulated by PI 3 kinase. Biochem Biophys Res Commun. 1999 Jan;254(1):231-42.

34 Garland CJ, Dora KA. EDH: endotheliumdependent hyperpolarization and microvascular signalling. Acta Physiol (Oxf). 2017 Jan; 219(1):152-61.

35 Fang JS, Angelov SN, Simon AM, Burt JM. $\mathrm{Cx} 40$ is required for, and cx37 limits, postischemic hindlimb perfusion, survival and recovery. J Vasc Res. 2012;49(1):2-12.

36 Fang JS, Angelov SN, Simon AM, Burt JM. $\mathrm{Cx} 37$ deletion enhances vascular growth and facilitates ischemic limb recovery. Am J Physiol Heart Circ Physiol. 2011 Nov;301 (5):H1872-81.

37 Pfenniger A, Wong C, Sutter E, Cuhlmann S, Dunoyer-Geindre S, Mach F, et al. Shear stress modulates the expression of the atheroprotective protein $\mathrm{Cx} 37$ in endothelial cells. J Mol Cell Cardiol. 2012 Aug;53(2):299-309.

38 Meens MJ, Pfenniger A, Kwak BR, Delmar M. Regulation of cardiovascular connexins by mechanical forces and junctions. Cardiovasc Res. 2013 Jul ;99(2):304-14.

39 Denis JF, Scheckenbach KEL, Pfenniger A, Meens MJ, Krams R, Miquerol L, et al. Connexin 40 controls endothelial activation by dampening NFkappaB activation. Oncotarget. 2017 Mar;8(31):50972-86.

40 Fang JS, Coon BG, Gillis N, Chen Z, Qiu J, Chittenden TW, et al. Shear-induced NotchCx37-p27 axis arrests endothelial cell cycle to enable arterial specification. Nat Commun. 2017 Dec;8(1):2149.

41 Bakker EN, Sorop O, Spaan JA, VanBavel E. Remodeling of resistance arteries in organoid culture is modulated by pressure and pressure pulsation and depends on vasomotion. Am J Physiol Heart Circ Physiol. 2004 Jun; 286(6):H2052-6.

42 Bolz SS, Pieperhoff S, De Wit C, Pohl U. Intact endothelial and smooth muscle function in small resistance arteries after $48 \mathrm{~h}$ in vessel culture. Am J Physiol Heart Circ Physiol. 2000 Sep;279(3):H1434-9.

43 Bevan JA, Kaley G, Rubanyi GM; American Physiological Society. Flow-dependent regulation of vascular function. New York: Oxford University Press; 1995.

44 Stepp DW, Nishikawa Y, Chilian WM. Regulation of shear stress in the canine coronary microcirculation. Circulation. 1999 Oct; 100(14):1555-61.

45 Bearden SE, Linn E, Ashley BS, Looft-Wilson RC. Age-related changes in conducted vasodilation: effects of exercise training and role in functional hyperemia. Am J Physiol Regul Integr Comp Physiol.2007 Oct;293(4):R171721.

46 Tsutsui M. Neuronal nitric oxide synthase as a novel anti-atherogenic factor. J Atheroscler Thromb. 2004;11(2):41-8.
47 Morishita T, Tsutsui M, Shimokawa $H$, Horiuchi M, Tanimoto A, Suda O, et al. Vasculoprotective roles of neuronal nitric oxide synthase. FASEB J. 2002 Dec;16(14):1994-6.

48 Furuno Y, Morishita T, Toyohira Y, Yamada S, Ueno S, Morisada N, et al. Crucial vasculoprotective role of the whole nitric oxide synthase system in vascular lesion formation in mice: Involvement of bone marrow-derived cells. Nitric Oxide. 2011 Oct 30;25(3):350-9.

49 Yogo K, Shimokawa H, Funakoshi H, Kandabashi T, Miyata K, Okamoto S, et al. Different vasculoprotective roles of NO synthase isoforms in vascular lesion formation in mice. Arterioscler Thromb Vasc Biol. 2000 Nov; 20(11):E96-100.

50 Troidl K, Tribulova S, Cai WJ, Ruding I, Apfelbeck $\mathrm{H}$, Schierling $\mathrm{W}$, et al. Effects of endogenous nitric oxide and of DETA NONOate in arteriogenesis. J Cardiovasc Pharmacol. 2010 Feb;55(2):153-60.

51 Buxton IL, Cheek DJ, Eckman D, Westfall DP, Sanders KM, Keef KD. NG-nitro L-arginine methyl ester and other alkyl esters of arginine are muscarinic receptor antagonists. Circ Res. 1993 Feb;72(2):387-95.

52 Heim KF, Thomas G, Ramwell PW. Superoxide production in the isolated rabbit aorta and the effect of alloxan, indomethacin and nitrovasodilators. J Pharmacol Exp Ther. 1991 Feb; 256(2):537-41.

53 Peterson DA, Peterson DC, Archer S, Weir EK. The non specificity of specific nitric oxide synthase inhibitors. Biochem Biophys Res Commun. 1992 Sep;187(2):797-801.

54 Dumont O, Loufrani L, Henrion D. Key role of the NO-pathway and matrix metalloprotease- 9 in high blood flow-induced remodeling of rat resistance arteries. Arterioscler Thromb Vasc Biol. 2007 Feb;27(2):317-24.

55 van der Heijden OW, Essers YP, Fazzi G, Peeters LL, De Mey JG, van Eys GJ. Uterine artery remodeling and reproductive performance are impaired in endothelial nitric oxide synthase-deficient mice. Biol Reprod. 2005 May;72(5):1161-8.

56 Yu J, Zhang Y, Zhang X, Rudic RD, Bauer PM, Altieri DC, et al. Endothelium derived nitric oxide synthase negatively regulates the PDGF-survivin pathway during flow-dependent vascular remodeling. PLoS One. 2012; 7(2):e31495.

57 Rudic RD, Bucci M, Fulton D, Segal SS, Sessa WC. Temporal events underlying arterial remodeling after chronic flow reduction in mice: correlation of structural changes with a deficit in basal nitric oxide synthesis. Circ Res. 2000 Jun;86(11):1160-6.

58 Martinez-Lemus LA, Galiñanes EL. Matrix metalloproteinases and small artery remodeling. Drug Discov Today Dis Models. 2011;8(1):21-8.

59 Martinez-Lemus LA, Hill MA, Meininger GA. The plastic nature of the vascular wall: a continuum of remodeling events contributing to control of arteriolar diameter and structure. Physiology (Bethesda). 2009 Feb; 24(1):45-57. 
60 Bakker EN, Pistea A, VanBavel E. Transglutaminases in vascular biology: relevance for vascular remodeling and atherosclerosis. J Vasc Res. 2008;45(4):271-8.

61 Bakker EN, Pistea A, Spaan JA, Rolf T, de Vries CJ, van Rooijen N, et al. Flow-dependent remodeling of small arteries in mice deficient for tissue-type transglutaminase: possible compensation by macrophage-derived factor XIII. Circ Res. 2006 Jul;99(1):86-92.

62 Bakker EN, Buus CL, Spaan JA, Perree J, Ganga A, Rolf TM, et al. Small artery remodeling depends on tissue-type transglutaminase. Circ Res. 2005 Jan;96(1):119-26.

63 Pistea A, Bakker EN, Spaan JA, Hardeman MR, van Rooijen N, VanBavel E. Small artery remodeling and erythrocyte deformability in L-NAME-induced hypertension: role of transglutaminases. J Vasc Res. 2008;45(1): $10-8$.

64 Bernassola F, Rossi A, Melino G. Regulation of transglutaminases by nitric oxide. Ann N Y Acad Sci. 1999;887(1):83-91.

65 Hakim CH, Jackson WF, Segal SS. Connexin isoform expression in smooth muscle cells and endothelial cells of hamster cheek pouch arterioles and retractor feed arteries. Microcirculation. 2008 Aug;15(6):503-14.

66 Shav D, Gotlieb R, Zaretsky U, Elad D, Einav $\mathrm{S}$. Wall shear stress effects on endothelial-endothelial and endothelial-smooth muscle cell interactions in tissue engineered models of the vascular wall. PLoS One. 2014 Feb; 9(2):e88304.

67 Kefaloyianni E, Coetzee WA. Transcriptional remodeling of ion channel subunits by flow adaptation in human coronary artery endothelial cells. J Vasc Res. 2011;48(4):357-67.

68 Johnson TL, Nerem RM. Endothelial connexin 37 , connexin 40 , and connexin 43 respond uniquely to substrate and shear stress. Endothelium. 2007 Jul-Oct;14(4-5):215-26.
69 Conway DE, Williams MR, Eskin SG, McIntire LV. Endothelial cell responses to atheroprone flow are driven by two separate flow components: low time-average shear stress and fluid flow reversal. Am J Physiol Heart Circ Physiol. 2010 Feb;298(2):H367-74.

70 Yao QP, Qi YX, Zhang P, Cheng BB, Yan ZQ, Jiang ZL. SIRT1 and Connexin40 Mediate the normal shear stress-induced inhibition of the proliferation of endothelial cells co-cultured with vascular smooth muscle cells. Cell Physiol Biochem. 2013;31(2-3):389-99.

71 Dolan JM, Sim FJ, Meng H, Kolega J. Endothelial cells express a unique transcriptional profile under very high wall shear stress known to induce expansive arterial remodeling. Am J Physiol Cell Physiol. 2012 Apr; 302(8):C1109-18.

72 Cai WJ, Koltai S, Kocsis E, Scholz D, Schaper W, Schaper J. Connexin37, not $\mathrm{Cx} 40$ and $\mathrm{Cx} 43$, is induced in vascular smooth muscle cells during coronary arteriogenesis. J Mol Cell Cardiol. 2001 May;33(5):957-67.

73 Vorderwulbecke BJ, Maroski J, Fiedorowicz K, Da Silva-Azevedo L, Marki A, Pries AR, et al. Regulation of endothelial connexin 40 expression by shear stress. American journal of physiology Heart and circulatory physiology. 2012;302(1):H143-52.

74 Gabriels JE, Paul DL. Connexin 43 is highly localized to sites of disturbed flow in rat aortic endothelium but connexin 37 and connexin 40 are more uniformly distributed. Circ Res. 1998 Sep;83(6):636-43.

75 Cowan DB, Lye SJ, Langille BL. Regulation of vascular connexin 43 gene expression by mechanical loads. Circ Res. 1998 Apr;82(7):78693.

76 DePaola N, Davies PF, Pritchard WF Jr, Florez L, Harbeck N, Polacek DC. Spatial and temporal regulation of gap junction connexin43 in vascular endothelial cells exposed to controlled disturbed flows in vitro. Proc Natl Acad Sci USA. 1999 Mar;96(6):3154-9.

77 Bao X, Clark CB, Frangos JA. Temporal gradient in shear-induced signaling pathway: involvement of MAP kinase, $c$-fos, and connexin43. Am J Physiol Heart Circ Physiol. 2000 May;278(5):H1598-605.
78 Kwak BR, Silacci P, Stergiopulos N, Hayoz D, Meda P. Shear stress and cyclic circumferential stretch, but not pressure, alter connexin 43 expression in endothelial cells. Cell Commun Adhes. 2005 Jul-Dec;12(5-6):261-70.

79 Zhang Z, Chen Y, Zhang T, Guo L, Yang W, Zhang J, et al. Role of Myoendothelial Gap Junctions in the Regulation of Human Coronary Artery Smooth Muscle Cell Differentiation by Laminar Shear Stress. Cell Physiol Biochem. 2016;39(2):423-37.

80 Woodman CR, Muller JM, Rush JW, Laughlin $\mathrm{MH}$, Price EM. Flow regulation of ecNOS and $\mathrm{Cu} / \mathrm{Zn}$ SOD mRNA expression in porcine coronary arterioles. Am J Physiol. 1999 Mar;276(3):H1058-63.

81 Woodman CR, Price EM, Laughlin MH. Shear stress induces eNOS mRNA expression and improves endothelium-dependent dilation in senescent soleus muscle feed arteries. J Appl Physiol (1985). 2005 Mar;98(3):940-6.

82 Lemkens P, Boari G, Fazzi G, Janssen G, Murphy-Ullrich J, Schiffers P, et al. Thrombospondin-1 in early flow-related remodeling of mesenteric arteries from young normotensive and spontaneously hypertensive rats. Open Cardiovasc Med J. 2012;6:50-9.

83 Huh YH, Zhou Q, Liao JK, Kitazawa T. ROCK inhibition prevents fetal serum-induced alteration in structure and function of organcultured mesenteric artery. J Muscle Res Cell Motil. 2011 Sep;32(2):65-76.

84 Martinez-Lemus LA, Zhao G, Galinanes EL, Boone M. Inward remodeling of resistance arteries requires reactive oxygen species-dependent activation of matrix metalloproteinases. Am J Physiol Heart Circ Physiol. 2011 Jun; 300(6):H2005-15.

85 Hagan C. When are mice considered old. Available from: https://wwwjaxorg/newsand-insights/jax-blog/2017/november/ when-are-mice-considered-old. 2017. 